\title{
STUDI KINERJA PEMASARAN EDEL CACAO: PERAN KUALITAS PRODUK DAN HARGA
}

\author{
Retno Cahyaningtyas Puji Lestari \\ Universitas Negeri Surabaya \\ retnolestari1@mhs.unesa.ac.id \\ Rosa Prafitri Juniarti \\ Universitas Negeri Surabaya \\ rosajuniarti@unesa.ac.id
}

\begin{abstract}
This study aims to investigate the marketing mix impact of product quality and prices on sales performance which is decomposed into the volume of sales, the volume of consumers, and volume bought each consumer, using longitudinal data. This study analyzes the decline sales phenomenon of Edel Cocoa in PT Perkebunan Nusantara XII (Persero) for five years in a row from 2014-2018 through the implementation strategy of product quality and price, with total 253 products sold and 241 consumer purchase transactions. Using three generalized estimating equations method at the real level $(\alpha)=5 \%$. The result indicates that the marketing mix of product quality and prices have a strong impact on sales volume and volume bought each consumer. However, the marketing mix of product quality and prices don't have a significant impact on the volume of consumers. The marketing mix of quality products and prices simultaneous in explaining sales performance is at $14.5 \%$ while the remaining $85.5 \%$ is explained by other factors not included in this research model.
\end{abstract}

Keywords: generalized estimating equation; marketing mix; marketing performance; price; product quality.

\section{PENDAHULUAN}

Asia merupakan pasar produk cokelat yang paling cepat berkembang di dunia, dengan tingkat pertumbuhan konsumsi sebesar 5\% pertahun. Salah satu pendorong utama pertumbuhan industri ini adalah perluasan kelas menengah ASEAN dan peningkatan PDB per kapita di negara-negara berkembang seperti Cina, Meksiko, Turki dan India, serta inovasi di industri makanan nasional berbahan dasar cokelat (iisd.org, 2019). Menurut Cocoa Association of Asia (2019), orang-orang yang semakin kaya cenderung mengonsumsi lebih banyak cokelat, roti, dan minum-minuman.

Cokelat adalah sebutan untuk hasil olahan makanan atau minuman dari biji kakao. Biji kakao umumnya diperoleh dari negara-negara yang berada di zona beriklim tropis di sekitar Khatulistiwa. Sekitar 71,1\% produksi kakao dunia dikirim dari negara-negara di Afrika seperti Pantai Gading, Ghana, dan Kamerun. Negara-negara penghasil kakao berikutnya secara berurutan adalah Indonesia, Nigeria, Brasil, Ekuador, Meksiko, Peru, dan Republik Dominika (fao.org, 2019).

Food and Agriculture Organisation of The United Nations (2019) menyatakan, ada sekitar 5,2 juta ton biji kakao yang diproduksi selama tahun 2018 untuk memasok permintaan cokelat yang terus meningkat di seluruh dunia (fao.org, 2019). Mempertimbangkan bahwa Afrika Barat kehabisan lahan untuk menanam kakao dan fakta bahwa produksi per hektarnya lebih rendah dari Malaysia (Schroth, Läderach, Martinez-Valle, Bunn, \& Jassogne, 2016) menjadikan Asia memiliki potensi untuk tumbuh dan membantu memenuhi permintaan akan kakao global yang terus meningkat.

Kakao sebagai komoditas perdagangan biasanya dibedakan menjadi dua kelompok besar, yaitu Kakao Mulia (Edel Cacao) dan Kakao Curah (Bulk Cacao). Edel cacao termasuk dalam kelompok fine or flavour cocoa (FFC). Fine cocoa adalah biji kakao dengan citarasa atau sifat khusus, khas-spesifik dan mendapatkan penghargaan atau apresiasi khusus dari peminatnya. Kakao tersebut tidak memiliki cacat cita rasa apapun dan dihasilkan dari daerah tertentu dengan cara-cara penanganan-pengolahan yang tertentu pula, selain sebagai bahan dasar pembuatan cokelat, kakao jenis ini juga digunakan 
sebagai bahan dasar pembuatan kosmetik. Kakao jenis ini hanya memasok kurang dari $10 \%$ produksi kakao dunia, dihasilkan oleh negara Equador, Venezuela, Trinidad, Grenada, Jamaika, Srilanka, dan Indonesia. 90\% lainnya dipasok dari jenis bulk cacao yang kebanyakan berasal dari negara-negara di Afrika. Karena karakteristiknya tersebut, edel cacao digolongkan sebagai specialty good di mana peminatnya bersedia memberikan apresiasi atas eksklusivitas dan kelangkaan produk dengan penetapan harga premium (ptpn12.com, 2019).

Di pasar komoditas, harga terbentuk melalui mekanisme pasar dan hasil kesepakatan bersama antara penjual dan pembeli. Agar pembeli bersedia membeli produk dengan harga yang lebih tinggi, produk yang dijual harus berkarakter. Banyak perusahaan mengadopsi eksklusivitas produk serta kelangkaan sebagai sarana untuk menekankan keunikan dan membenarkan penetapan harga premium. Keunikan dan kualitas produk menjadi faktor pendukung yang sangat penting. Sebab, perusahaan yang bersaing di pasar ini tidak cocok menggunakan banyak teknik pemasaran. Umumnya, konsumen hanya akan mementingkan faktor harga dan kualitas (Karam, A. A., et al, 2018). Konsumen akan memilih produk karena kualitas yang bagus dan harga yang mungkin terjangkau (Allaoui mohammed elhassen, et al 2017), dan beberapa konsumen lainnya akan membeli dengan harga yang lebih tinggi atas presepsi kualitas yang lebih baik (Kotler dan Keller, 2009: 74).

PT Perkebunan Nusantara XII (Persero) merupakan salah satu BUMN (Badan Usaha Milik Negara) yang bergerak dibidang agribisnis perkebunan, mengelola lima budidaya tanaman (karet, kopi, teh, tebu, kakao, dan aneka jenis kayu) salah satunya adalah budidaya edel cacao (bumn.go.id, 2011). Sebagai satu-satunya perusahaan yang memproduksi edel cacao di Indonesia (cnnindonesia.com, 2018), jangkauan pasarnya meliputi pasar lokal dan ekspor. Melalui hubungan kerjasama internasional seperti International Cocoa Organization-ICCO dan Federation of Cocoa CommerceFFC yang beranggotakan negara-negara produsen dan konsumen kakao dari seluruh dunia, PT Perkebunan Nusantara XII menjalin hubungan kerjasama yang erat dengan ikut aktif mendorong perekonomian kakao dunia, mempromosikan dan mendorong konsumsi cokelat global, serta memperlancar kegiatan ekspor-impor kakao Indonesia ke pasar internasional.

Pemasaran dilakukan secara langsung baik personal selling dan direct email/catalog pada berbagai penyelenggaran event-event kakao nasional dan internasional serta menjalin hubungan kerjasama baik dengan pihak swasta nasional maupun internasional. Dengan berfokus pada segmen pasar yang bersifat niche market perusahaan mampu bersaing untuk meraih penghargaan pembeli berupa harga premium di atas harga bursa. Penjualan dilaksanakan dengan free sale atau sistem penjualan berdasarkan stok dengan sistem forward sale. Mempertahankan pasar yang sudah ada dengan pengaturan komposisi kuantum penjualan kepada masing-masing pembeli. Sementara, produk didistribusian langsung dari PT Perkebunan Nusantara XII di Surabaya (Annual Report PTPN XII, 2018).

Sebagai produk komoditas unggulan harga jual edel cacao sangat dipengaruhi oleh fluktuasi harga di bursa pasar internasional. Di tengah tantangan bisnis yang fluktuatif tersebut, untuk dapat bersaing dengan negara-negara produsen edel cacao lainnya, PT Perkebunan Nusantara XII secara masif berupaya melakukan pembenahan dengan cara konsisten terhadap kualitas produk yang dihasilkan (Annual Report PTPN XII, 2018).

Pada 2012, Edel Cacao PT Perkebunan Nusantara XII pernah mengalami lonjakan permintaan hingga membuat harga jualnya meningkat tujuh kali lipat. Hal itu merupakan capaian tertinggi sejak Edel Cacao Indonesia mulai diperdagangkan di bursa komoditas dunia. Namun kinerja pemasaran edel cacao terus mengalami penurunan setelahnya. Tahun 2019, PT Perkebunan Nusantara XII menyatakan, produksi edel cacao tahun 2018 meningkat sebesar $11 \%$ menjadi 313 ton dibandingkan tahun 2017 sebesar 282 ton. Kuantum penjualannya mencapai 252 ton, meningkat sebesar 18\% dibandingkan tahun 2017. Namun nilai penjualan berkurang sebesar 24\% menjadi Rp12 miliar. Penjualan edel cacao ditujukan untuk pasar ekspor sebesar 87,5 ton $(34,5 \%)$ dan untuk pasar lokal sebesar 165 ton $(65,5 \%)$, ekspor edel cacao telah menurun sebesar $46 \%$ dari tahun sebelumnya 
Retno Cahyaningtyas Puji Lestari. Studi Kinerja Pemasaran Edel Cacao: Peran Kualitas Produk dan Harga

dikarenakan permintaan akan edel cacao menurun di pasar Eropa dan Amerika. Dengan harga jual lebih rendah dibandingkan tahun 2017 (Annual Report PTPN XII, 2018).

Selama kurun waktu 2014 sampai dengan 2018, kinerja pemasaran Edel Cacao PT Perkebunan Nusantara XII memiliki tren menurun. Penurunan pada produksi edel cacao sebesar 2,9\% per tahun. Penjualan untuk pasar ekspor menurun sebesar $27,7 \%$ per tahunnya, sementara penjualan untuk pasar lokal meningkat $76,9 \%$ dengan penurunan pada pendapatan penjualan sebesar $18,5 \%$ per tahun dan penurunan pada volume penjualan rata-rata sebesar 0,08\% per tahunnya (Penjualan Kakao Edel PTPN XII, 2010-2019).

Volume penjualan paling banyak digunakan sebagai model dari respon penerapan strategi pemasaran. Volume penjualan menjadi lebih tinggi atau lebih rendah, dapat disebabkan oleh banyaknya pembeli dengan pembelian normal/ rendah (mengidentifikasi ukuran dari ekspansi pangsa pasar) atau disebabkan oleh banyaknya produk yang dibeli oleh pelanggan (yang mengidentifikasi loyalitas konsumen) (R. Porto \& Lima, 2015). Ketika volume penjualan dikalikan dengan harga maka dapat diintegrasikan sebagai ukuran kinerja perusahaan seperti pendapatan kotor dan pertumbuhan bisnis (Farris, et al, 2010). Penelitian ini bertujuan untuk mengidentifikasi apa penyebab penurunan penjualan edel cacao melalui evaluasi penerapan kebijakan bauran pemasaran PT Perkebunan Nusantara XII yaitu strategi kualitas produk dan harga terhadap kinerja pemasaran yang didekomposisi menjadi volume penjualan, jumlah konsumen dan tingkat pembelian per konsumen.

\section{KAJIAN PUSTAKA DAN PENGEMBANGAN HIPOTESIS}

\section{Bauran Pemasaran}

Bauran pemasaran adalah sebuah konsep yang digunakan untuk mendeskripsikan empat kombinasi inti dari sistem pemasaran perusahaan yaitu produk, sistem distribusi, struktur harga dan kegiatan promosi (William J. Stanston, 2006: 30). Bauran pemasaran juga dapat didefinisikan sebagai serangkaian instrumen pemasaran yang dirancang perusahaan dalam mencapai target pemasaran di pasar sasarannya. Instrument pemasaran tersebut diklasifikasi menjadi empat yaitu, product (produk), price (harga), place (distribusi), dan promotion (promosi) atau yang dikenal sebagai $4 p$ (Kotler dan Amstrong, 2012: 62).

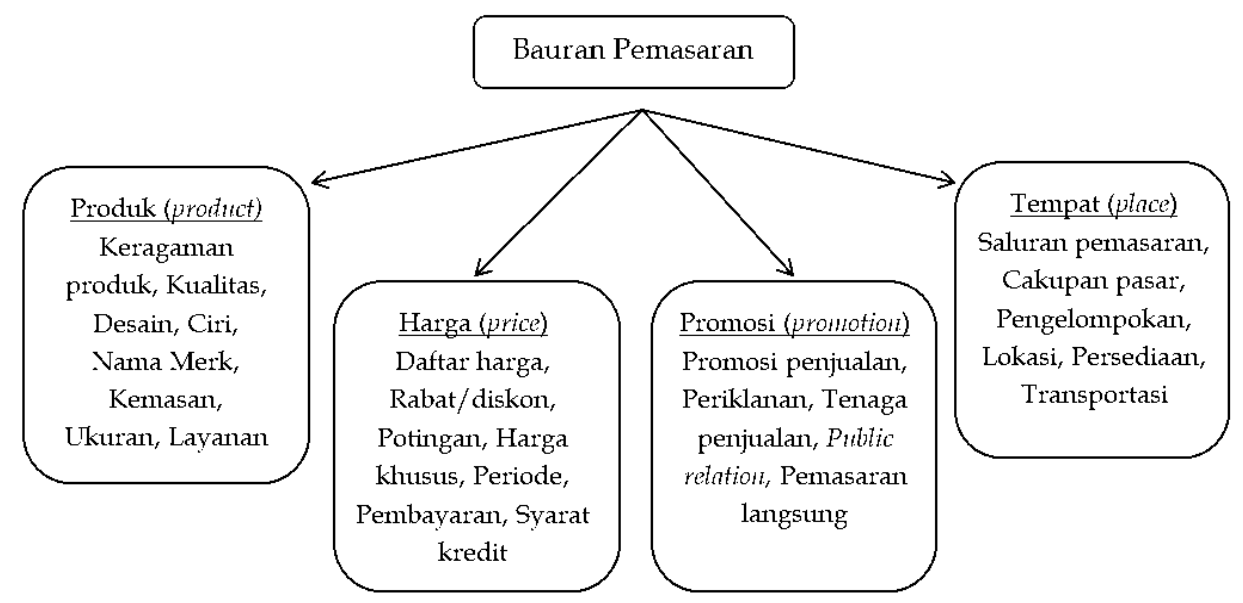

Sumber: Kotler dan Amstrong (2012: 62)

Gambar 1. 4P DALAM BAURAN PEMASARAN

\section{Kualitas Produk}

Produk didefinisikan sebagai segala sesuatu yang diproduksi untuk kemudian ditawarkan agar mendapat perhatian, permintaan, dicari dan dibeli oleh konsumen sebagai pemenuhan atas kebutuhan atau keinginannya (Tjiptono, 2008: 95). Kualitas produk adalah keseluruhan atribut produk yang mampu memuaskan kebutuhan konsumen baik secara eksplisit ataupun implisit (Kotler dan Keller, 2009: 143). Tjiptono (2008: 51) mendefinisikan lima aspek kualitas, yaitu (a) Transcendental approach yaitu kualitas dapat dirasakan atau diketahui tetapi sulit untuk didefinisikan dan 
dioperasikan, biasanya berupa pesan komunikasi; (b) Product based approach yaitu kualitas merupakan karakteristik atau atribut yang dapat dikuantitatifkan dan dapat diukur. Perbedaan kualitas dicerminkan melalui perbedaan dalam berapa jumlah atribut yang dimiliki produk; (c) User based approach yaitu kualitas tergantung pada orang yang melihatnya, sehingga produk yang paling memuaskan preferensi seseorang merupakan produk berkualitas tinggi; (d) Manufacturing based approach yaitu pendekatan yang berfokus pada penyesuaian spesifikasi yang dikembangkan secara internal atau merupakan standar yang telah ditetapkan perusahaan; (e) Value based approach yaitu pendekatan yang memandang kualitas dari segi nilai dan harga, dengan mempertimbangkan antara kualitas produk dan harga. Sehingga produk yang paling dinilai adalah barang atau jasa yang paling tepat dibeli.

\section{Harga}

Harga adalah nilai tukar yang dikeluarkan konsumen untuk memperoleh manfaat dari memiliki atau mengkonsumsi barang atau jasa (Kotler dan Amstrong, 2012: 430). Satu-satunya komponen bauran pemasaran yang menghasilkan pemasukan (pendapatan) bagi perusahaan adalah harga, sementara komponen bauran pemasaran lainnya (produk, distribusi, dan promosi) menimbulkan pengeluaran (biaya) (Tjiptono, 2008: 151). Lebih lanjut, Tjiptono mengklasifikasikan lima tujuan penetapan harga, yaitu (a) Berorientasi pada laba yaitu harga ditetapkan sedemikian rupa agar mencapai tingkat laba maksimum yang diharapkan; (b) Berorientasi pada volume yaitu menetapkan harga dengan mempertimbangkan target volume penjualan, nilai penjualan atau pangsa pasar yang hendak dituju; (c) Berorientasi pada citra, jika tujuan perusahaan adalah untuk membentuk atau mempertahankan citra prestisius maka cenderung menetapkan harga tinggi dan sebaliknya perusahaan akan menetapkan harga rendah untuk membangun citra tertentu (image of product); (d) Stabilisasi harga yaitu di mana harga yang ditetapkan bertujuan untuk mempertahankan stabilisasi harga dalam suatu industri (antara perusahaan dengan pemimpin industri); (e) Tujuan-tujuan lainnya yaitu harga dapat ditetapkan dengan tujuan mencegah masuknya pesaing, mempertahankan loyalitas pelanggan, mendukung penjualan ulang atau menghindari campur tangan pemerintah.

Menurut Kotler (2012: 77) faktor-faktor yang perlu diperhatikan dalam penetapan harga yaitu biaya produksi, permintaan dan penawaran, serta keadaan ekonomi. Sedangkan, menurut Tjiptono (2008: 152), secara umum ada faktor yang perlu diperhatikan dalam penetapan harga antara lain adalah (a) Penetapan harga berbasis permintaan, yaitu menekankan faktor-faktor yang mempengaruhi perilaku konsumen secara langsung; (b) Penetapan harga berbasis biaya, yaitu harga ditentukan berdasarkan aspek HPP; (c) Penetapan harga berbasis laba, yaitu memperhitungkan pendapatan dan biaya dalam penetapan harganya agar memperoleh target laba; (d) Penetapan harga berbasis persaingan, yaitu harga ditentukan dengan mempertimbangkan harga dari produk pesaing.

\section{Kinerja Pemasaran}

Kinerja adalah praktik yang berhubungan dengan segala aktivitas dan prestasi. Konsep yang digunakan untuk mengukur prestasi dari aktivitas pemasaran secara menyeluruh disebut kinerja pemasaran. Kinerja pemasaran merupakan titik standar overspent dan underdelivered, karena tidak mudah mengukur efektifvitas dan efisiensi dari setiap aktivitas, keputusan atau program pemasaran (Tjiptono, 2008: 239). Kinerja pemasaran lebih obyektif dan terkonsentrasi pada produktivitas dan profitabilitas. Kinerja pemasaran juga diartikan sebagai usaha mengukur omzet penjualan, jumlah pelanggan, keuntungan, dan pertumbuhan penjualan (Voss, et al 2000).

Menurut Ferdinand (2000: 125), kinerja pemasaran yang baik dapat dinyatakan dalam tiga besaran utama, yaitu: nilai penjualan, pertumbuhan penjualan, dan pangsa pasar/ market share. Menurut Pelham \& Wilson (1996), tiga indikator kinerja pemasaran, yaitu efektivitas perusahaan, pertumbuhan penjualan, dan pertumbuhan keuntungan relatif. Dalam penelitian ini, ukuran kinerja pemasaran mengacu pada Froehle et al., (2000) dan Porto \& Lima, (2015) yang dibentuk oleh tiga indikator, yaitu volume penjualan, jumlah pelanggan, dan tingkat pembelian produk per konsumen.

\section{Volume Penjualan}



Harga

Penjualan adalah aktivitas mencari pembeli, mempengaruhi dan menyampaikan informasi kepada calon pembeli agar mereka dapat menyesuaikan kebutuhannya dengan produk yang ditawarkan serta melakukan kesepakatan harga agar kedua belah pihak saling diuntungkan (Moekijat, 2000: 488). Penjualan juga dapat diartikan sebagai keseluruhan sistem dan kegiatan merencanakan, menentukan harga, melakukan promosi dan mendistribusikan barang atau jasa kepada pembeli dan calon pembeli untuk memenuhi dan memuaskan kebutuhan mereka (William J. Stanston dalam Basu Swastha dan Irawan, 2008:7).

Menurut John Downes dan Jordan Elliot Goodman (dalam Susanto Budidharmo, 2000: 646) mejelaskan bahwa volume penjualan adalah total penjualan yang di dapat dari komoditas yang diperdagangkan dalam suatu masa tertentu. Lebih lanjut menurut Winardi (2001:359) mengatakan bahwa volume penjualan adalah hasil penjualan yang dinyatakan dalam bentuk kualitatif, fiskal atau volume. Volume penjualan merupakan variabel dependen yang paling banyak digunakan dalam model respon dari kegiatan pemasaran. Volume penjualan mewakili sejumlah produk yang dibeli konsumen. Pertumbuhan volume penjualan dapat dijelaskan oleh pertumbuhan tingkat pembelian produk per konsumen atau pertumbuhan jumlah konsumen (Porto \& Lima, 2015). Pertumbuhan merupakan perubahan kenaikan atau penurunan dari satu periode ke periode selanjutnya yang ditentukan secara berurutan.

\section{Hubungan antar Variabel}

R. B. Porto, de Oliveira-Castro, \& Seco-Ferreira (2011) dalam penelitiannya menyebutkan bahwa, produk yang berkualitas cenderung mendorong konsumen untuk melakukan perencanaan pembelian ulang. Basu Swastha (2008: 406) menyebutkan salah satu faktor yang mempengaruhi penjualan adalah karakteristik produk yang ditawarkan. Saragih (2017) dalam penelitiannya mengungkapkan bahwa kualitas produk berpengaruh signifikan terhadap volume penjualan ekspor. Kemudian, Swastha dan Handoko (2012: 77) juga menyatakan bahwa motivasi seseorang dalam melakukan pembelian produk dipengaruhi oleh kelengkapan produk, yaitu meliputi mutu. Lebih lanjut, Adewale et al (2013) dalam penelitiannya menyatakan bahwa kualitas produk berpengaruh signifikan terhadap kinerja bisnis terutama pada peningkatan pangsa pasar dan ekspansi.

Foxall (2009) dalam penelitiannya menjelaskan bahwa setiap konsumen cenderung untuk membeli lebih banyak pada setiap kesempatan berbelanja ketika harga yang ditawarkan lebih rendah. Lebih lanjut, dalam penelitian R. Porto \& Lima (2015) mengungkapkan bahwa diskon harga berpengaruh signifikan pada peningkatan volume penjualan. Baru Swastha (2008: 406) menyebutkan salah satu faktor yang mempengaruhi volume penjualan adalah harga. Kemudian, dalam penelitian yang dilakukan oleh Dwijayani (2013), menyatakan bahwa secara bersama-sama harga, lokasi dan kualitas layanan berpengaruh signifikan terhadap volume penjualan. Olasunkanmi (2013) dalam penelitiannya menyatakan bahwa terdapat hubungan yang signifikan antara harga dan kinerja bisnis. R. Porto \& Lima (2015) menyatakan setiap variabel independen (branding, harga, ketersediaan dan komunikasi) dalam penelitiannya memiliki pengaruh yang signifikan dan memiliki besaran pengaruh yang tidak sama pada kinerja pemasaran dikomposisi menjadi volume penjualan, volume konsumen dan pembelian per konsumen. Di pasar lebih elastis, penjualan unit akan naik atau turun lebih responsif sebagai respons terhadap perubahan harga (Oliveira-castro, James, \& Foxall, 2007)

Adapun kerangka berpikir yang dibuat untuk mengetahui apakah harga dan kualitas produk berpengaruh terhadap kinerja penjualan dan pengurainya menjadi volume penjualan, jumlah pelanggan dan pembelian per konsumen edel cacao PT Perkebunan Nusantara XII (Persero), dapat dilihat pada gambar 2 . 


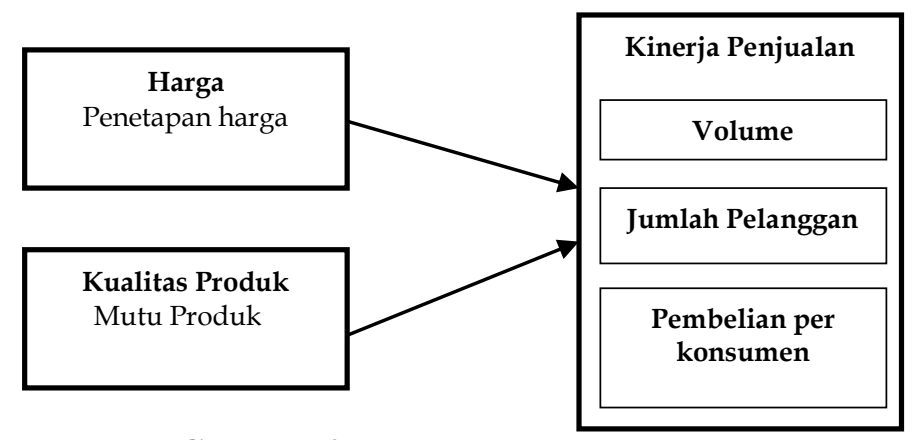

Gambar 2. KERANGKA BERPIKIR

\section{Hipotesis}

H1: Kualitas produk dan harga berpengaruh positif terhadap volume penjualan edel cacao periode 2014-2018.

$\mathrm{H} 2$ : Kualitas produk dan harga berpengaruh positif terhadap pertumbuhan jumlah konsumen edel cacao periode 2014-2018.

H3: Kualitas produk dan harga berpengaruh positif terhadap tingkat pembelian produk per konsumen periode 2014-2018.

\section{METODE PENELITIAN}

Untuk menilai pengaruh dari bauran pemasaran penelitian ini menggunakan catatan longitudinal. Pada studi longitudinal, setiap objek penelitian diukur selama periode waktu tertentu, sehingga data dikumpulkan pada beberapa titik waktu dan dilakukan pengukuran berulang pada objek tersebut. Pada data longitudinal, dimungkinkan untuk mempelajari perubahan respons antar waktu beserta faktor yang mempengaruhi perubahan tersebut, baik pada level populasi maupun level individu. Pengamatan longitudinal merupakan pengamatan yang menggabungkan antara pengamatan cross section dan time series. Kelebihan pengamatan longitudinal dari pengamatan yang lain yaitu mampu memberikan informasi tentang dinamika perubahan pada data cross section dari waktu ke waktu (Harlan, 2018). Namun pengukuran secara berulang pada pengamatan longitudinal dapat menyebabkan terjadinya autokorelasi. Untuk memodelkan data yang mengandung autokorelasi penelitian ini menggunakan metode Generalized Estimating Equation (GEE) sebagai metode yang digunakan dalam mencari hasil, membuktikan keakuratan hasil analisis dan memberikan suatu penjelasan atas fenomena dalam penelitian ini.

Tujuan penggunaan data longitudinal dalam penelitian ini adalah untuk mengetahui apakah ada pengaruh variabel independen terhadap variabel dependen, termasuk meneliti pengaruh variabel independen pada besarnya perubahan pada variabel dependen. Unit analisis adalah (1) total penjualan bulanan selama tahun 2014-2018, menunjukkan variabel dependen-volume penjualan; (2) jumlah konsumen setiap bulan selama tahun 2014-2018, sebagai variabel dependen jumlah konsumen; dan (3) daftar konsumen dengan produk yang dibeli oleh masing-masing konsumen, mewakili volume variabel dependen tingkat pembelian produk per konsumen.

Sumber data dalam penelitian ini berupa data sekunder berbentuk kuantitatif berupa angka yang terukur, rasional, dan sistematis. Populasi dalam penelitian ini adalah laporan penjualan Edel Cacao PT Perkebunan Nusantara XII (Persero) sejak awal beroperasi hingga tahun 2019. Adapun sampel penelitian ini adalah data penjualan Edel Cacao selama lima tahun terhitung mulai tahun 2014-2018. Data penjualan edel cacao tersebut mencantumkan tujuh tingkat kualitas edel cacao; 1 -AA DB=20\% (high grade 1); 1-AA DB=60\% (high grade 2); 1-Sa (local grade 1); 1-Sc (local grade 2); $\mathrm{BKH}$ (low grade 1); BP (low grade 2); KEPEK (log grade 3), harga unit, tanggal penjualan, daftar pelanggan dengan total 253 produk terjual dan 241 transaksi pembelian selama 2014-2018. Ukuran sampel ini disajikan dengan interval kepercayaan $95 \%$.

\section{HASIL DAN PEMBAHASAN}


Retno Cahyaningtyas Puji Lestari. Studi Kinerja Pemasaran Edel Cacao: Peran Kualitas Produk dan Harga

\section{Uji Hipotesis}

Asumsi ini diuji menggunakan pengujian spherecity mauchly. Kualitas produk dan harga yang diukur secara berulang dengan total 253 unit produk terjual selama lima tahun. Keluaran nilai mauchly berfungsi untuk menguji apakah matriks kovarian pada semua variabel dependen yang dibandingkan sama. Hasil keluaran menunjukkan uji spherecity mauchly pada kinerja pemasaran dengan kualitas produk dan harga sebagai varian dan kovarian menunjukkan Mauchly's W nilai sebesar 1. Angka 1 memiliki arti bahwa matriks kovarian membentuk lingkaran (spherecity). Maka prosedur yang sudah dijalankan tidak melanggar asumsi spherecity dan data yang dianalisis sudah memenuhi persyaratan.

Pada tabel 1 (KINERJA_PEMASARAN), nilai sig. pada kolom Sig, untuk nilai-nilai Sphericity Assumed, Greenhouse-Geisser, Huynh-Feldt dan Lower-bound semua menunjukkan nilai 0,000 yang lebih kecil dari 0,05. Dengan demikian model yang dibuat dengan dasar variabel dependen kinerja pemasaran dan variabel independen kualitas produk dan harga sudah benar atau layak. Artinya, kualitas produk dan harga secara simultan berpengaruh signifikan terhadap kinerja pemasaran; volume penjualan dan jumlah pelanggan. Besarnya pengaruh kualitas produk dan harga secara simultan ialah sebesar 0,145 (14,5\%) sebagaimana tertera dalam kolom partial eta squared.

\section{Tabel 1}

TEST OF WITHIN-SUBJECTS EFFECTS

\begin{tabular}{llrrrr}
\hline & Source & df & \multicolumn{1}{c}{ F } & Sig. & Partial Eta Squared \\
\hline KINERJA_ & Sphericity Assumed & 1 & 41,436 &, 000 &, 145 \\
PEMASARAN & Greenhouse-Geisser & 1,000 & 41,436 &, 000 &, 145 \\
& Huynh-Feldt & 1,000 & 41,436 &, 000 &, 145 \\
& Lower-bound & 1,000 & 41,436 &, 000 &, 145 \\
KINERJA__ & Sphericity Assumed & 1 & 7,908 &, 005 &, 031 \\
PEMASARAN * & Greenhouse-Geisser & 1,000 & 7,908 &, 005 &, 031 \\
HARGA & Huynh-Feldt & 1,000 & 7,908 &, 005 &, 031 \\
& Lower-bound & 1,000 & 7,908 &, 005 &, 031 \\
KINERJA__ & Sphericity Assumed & 6 & 12,148 &, 000 &, 229 \\
PEMASARAN * & Greenhouse-Geisser & 6,000 & 12,148 &, 000 &, 229 \\
KUALITAS_ & Huynh-Feldt & 6,000 & 12,148 &, 000 &, 229 \\
PRODUK & Lower-bound & 6,000 & 12,148 &, 000 &, 229 \\
\hline
\end{tabular}

Sumber: Hasil Penelitian, 2020 (data diolah)

Didasarkan pada nilai signifikansi berikutnya pada kolom (KINERJA PEMASARAN*HARGA) menunjukkan nilai signifikansi sebesar $0,005<0,05$, dengan demikian model kinerja pemasaran dengan variabel independen sudah benar atau layak. Besarnya pengaruh variabel harga terhadap kinerja pemasaran adalah sebesar 0,031 (3\%) sebagaimana tertera dalam kolom partial eta squared.

Pada kolom (KINERJA PEMASARAN*KUALITAS PRODUK) menunjukkan nilai signifikansi sebesar $0,000<0,05$, dengan demikian model kinerja pemasaran dengan variabel independen kualitas produk sudah benar dan layak. Besarnya pengaruh variabel kualitas produk terhadap kinerja pemasaran adalah sebesar 0,229 (22,9\% dibulatkan 23\%) sebagaimana tertera dalam kolom partial eta squared.

Tabel 2

CATEGORICAL VARIABEL INFORMATION

\begin{tabular}{llrr}
\hline & Factor & N & Percent \\
\hline KUALITAS & 1-AA-FC/W DB=20\% & 41 & $17,0 \%$ \\
PRODUK & 1-AA-FC/W DB=60\% & 42 & $17,4 \%$ \\
& 1-Sa-FC/W & 48 & $19,9 \%$ \\
& 1-Sc-FC/W & 28 & $11,6 \%$ \\
& BKH-FC/W SKB & 35 & $14,5 \%$ \\
& BP-FC/W & 18 & $7,5 \%$ \\
\hline
\end{tabular}




\begin{tabular}{lrr}
\hline KEPEK-FC/W & 29 & $12,0 \%$ \\
Total & 241 & $100,0 \%$ \\
\hline
\end{tabular}

Sumber: Hasil Penelitian, 2020 (data diolah)

Tabel 2 di atas memberikan penjelasan mengenai informasi variabel kategorikal kualitas produk pada pengukuran tingkat pembelian per konsumen dengan total 241 transaksi. Terdapat sebanyak 48 atau 19,9\% konsumen memilih kualitas produk 1-Sa atau local grade 1, kemudian secara berurutan konsumen memilih kualitas 1 -AA $\mathrm{DB}=60 \%$ atau high grade 2 sebesar 42 atau 17,4\%, kualitas 1-AA $\mathrm{DB}=20 \%$ atau high grade 1 sebesar 41 atau $17 \%$, kualitas $\mathrm{BKH}$ atau low grade 1 sebesar 35 atau 14,5\%, kualitas KEPEK atau low grade 3 sebesar 29 atau 12\%, kualitas 1-Sc atau local grade 2 sebesar 28 atau 11,6\%, dan kualitas BP atau low garde 2 sebesar 18 atau 7,5\%. Penelitian ini menjawab tiga kualitas kakao yang paling diminati secara berurutan adalah kualitas 3 (1-Sa-FC/W atau local grade 1), kemudian kualitas 2 (1-AA-FC/W DB=60\% atau high grade 2), dan kualitas 1 (1$\mathrm{AA}-\mathrm{FC} / \mathrm{W} \mathrm{DB}=20 \%$ atau high grade 1 ), mengindikasi bahwa konsumen cenderung berminat pada high quality product yang memiliki harga begitu tinggi.

Pada model Generalized Estimating Equations (Tabel 3) di bawah ini memberikan informasi mengenai peran kualitas produk dan harga pada kinerja pemasaran edel cacao yang didekomposisi menjadi volume penjualan, jumlah konsumen, dan tingkat pembelian per konsumen. Menganalisis bagaimana fenomena penurunan penjualan edel cacao terjadi yang mungkin dapat disebabkan oleh berkurangnya jumlah konsumen atau oleh menurunnya kuantitas produk yang dibeli per konsumen.

Tabel 3

MODEL GENERALIZED ESTIMATING EQUATIONS

\begin{tabular}{|c|c|c|c|}
\hline \multirow{2}{*}{ Source } & \multicolumn{3}{|c|}{ Type III } \\
\hline & Wald Chi-Square & df & Sig. \\
\hline VOLUME_PENJUALAN (Intercept) & 41,441 & 1 & ,000 \\
\hline KUALITAS_PRODUK & 72,884 & 6 & 000 \\
\hline HARGA & 7,908 & 1 & 005 \\
\hline JUMLAH_KONSUMEN (Intercept) & 15,388 & 1 & ,000 \\
\hline KUALITAS_PRODUK & 5,724 & 6 & ,455 \\
\hline HARGA & 1,641 & 1 & 200 \\
\hline TINGKAT_PEMBELIAN_PER_KONSUMEN (Intercept) & 62,782 & 1 & 000 \\
\hline KUALITAS_PRODUK & 88,616 & 6 & 000 \\
\hline HARGA & 15,214 & 1 & ,000 \\
\hline $\begin{array}{l}\text { Dependent Variabel: VOLUME PENJUALAN, JUMLAH } \\
\text { TINGKAT PEMBELIAN PER KONSUMEN }\end{array}$ & ONSUMEN, & & \\
\hline
\end{tabular}

Sumber: Hasil Penelitian, 2020 (data diolah)

Berdasarkan tabel 3 di atas memberikan informasi bahwa, volume penjualan memiliki nilai wald chisquare hitung untuk kualitas produk sebesar 72,884 dengan DF (Degree of Freedom) sebesar 6 dan Alpha $(\alpha)$ sebesar 0,05 . Diperoleh nilai chi-square hitung sebesar 72,884 > nilai chi-suare tabel sebesar 12,592; maka H0 diterima. Artinya faktor kualitas produk berpengaruh signifikan terhadap volume penjualan. Variabel harga juga memiliki nilai chi-square hitung sebesar 7,908 > nilai chisquare tabel 3,841, dengan DF sebesar 1 dan $\alpha=0,05$. Maka H0 diterima. Artinya baik faktor kualitas produk dan harga keduanya berpengaruh signifikan terhadap volume penjualan. Pada pengukuran estimasi parameter GEE menunjukkan kontribusi variabel independen; kualitas produk dan harga yang digunakan untuk memprediksi nilai variabel dependen volume penjualan, menunjukkan kualitas produk 1-AA $\mathrm{DB}=20 \%$ / high grade 1 berpengaruh terhadap volume penjualan sebesar 26.191,4 secara signifikan karena nilai sig $0,00<0,05$; Kualitas produk $1-\mathrm{AA} \mathrm{DB}=60 \%$ / high grade 2 berpengaruh terhadap volume penjualan sebesar 22.915,4 secara signifikan karena nilai sig $0,00<$ 0,05; Kualitas produk 1-Sa / local grade 1 berpengaruh terhadap volume penjualan sebesar 4.746,3 secara signifikan karena nilai sig 0,08 < 0,05; Kualitas produk 1-Sc / local grade 2 berpengaruh 

Harga

terhadap volume penjualan sebesar 3.538,1 secara signifikan karena nilai sig 0,037<0,05; Kualitas produk BKH / low grade 1 berpengaruh terhadap volume penjualan sebesar 959,2 secara tidak signifikan karena nilai sig 0,576 >0,05; Kualitas produk BP / low grade 2 berpengaruh terhadap volume penjualan sebesar -173,1 secara tidak signifikan karena nilai sig 0,929<0,05 dan kovariat harga berpengaruh terhadap volume penjualan sebesar $-0,11$ secara signifikan karena nilai sig $0,05 \leq$ 0,05 .

Selanjutnya jumlah konsumen memiliki nilai pada wald chi-square hitung untuk kualitas produk sebesar 5,724 dengan DF (Degree of Freedom) sebesar 6 dan Alpha $(\alpha)$ sebesar 0,05. Maka diperoleh nilai chi-square hitung sebesar 5,724 < nilai chi-suare tabel sebesar 12,592; maka H0 ditolak. Artinya faktor kualitas produk tidak berpengaruh signifikan terhadap jumlah konsumen. Sementara, variabel harga juga memiliki nilai chi-square sebesar hitung sebesar 1,641 < nilai chi-square tabel sebesar 3,841 , dengan DF sebesar 1 dan $\alpha=0,05$. Maka H0 ditolak. Artinya faktor harga tidak berpengaruh signifikan terhadap jumlah konsumen. Artinya, baik kualitas produk dan harga tidak berpengaruh terhadap pertumbuhan jumlah konsumen. Pada pengukuran estimasi parameter GEE menunjukkan kontribusi variabel independen; kualitas produk dan harga yang digunakan untuk memprediksi nilai variabel dependen jumlah konsumen, menunjukkan kualitas produk 1 -AA $\mathrm{DB}=20 \%$ / high grade 1 berpengaruh terhadap jumlah konsumen sebesar 3,39 secara tidak signifikan karena nilai sig 0,228 > 0,05 ; Kualitas produk 1-AA DB=60\% / high grade 2 berpengaruh terhadap jumlah konsumen sebesar 3,10 secara tidak signifikan karena nilai sig 0,206 > 0,05; Kualitas produk 1-Sa / local grade 1 berpengaruh terhadap jumlah konsumen sebesar 1,08 secara tidak signifikan karena nilai sig 0,356 > 0,05; Kualitas produk 1-Sc / local grade 2 berpengaruh terhadap jumlah konsumen sebesar 1,02 secara tidak signifikan karena nilai sig 0,337 >0,05; Kualitas produk BKH / low grade 1 berpengaruh terhadap jumlah konsumen sebesar 1,16 secara tidak signifikan karena nilai sig 0,240 > 0,05; Kualitas produk BP / low grade 2 berpengaruh terhadap jumlah konsumen sebesar $-0,93$ secara tidak signifikan karena nilai sig 0,326>0,05 dan harga berpengaruh terhadap volume penjualan sebesar 3,9088888 secara tidak signifikan karena nilai sig $0,200>0,05$.

Lebih lanjut pada tingkat pembelian per konsumen menunjukkan nilai wald chi-square hitung untuk kualitas produk sebesar 88,616 dengan DF (Degree of Freedom) sebesar 6 dan Alpha $(\alpha)$ sebesar 0,05. Maka diperoleh nilai chi-square hitung sebesar 88,616 > nilai chi-suare tabel sebesar 12,592; maka H0 diterima. Artinya faktor kualitas produk berpengaruh signifikan terhadap tingkat pembelian produk per konsumen. Dan variabel harga memiliki nilai chi-square hitung sebesar 15,214 dengan DF sebesar 1 dan $\alpha=0,05$. Maka diperoleh chi-square hitung sebesar 15,214 > nilai chi-square tabel sebesar 3,841; maka H0 diterima. Artinya baik faktor kualitas produk dan harga berpengaruh signifikan terhadap tingkat pembelian produk per konsumen. Pada pengukuran estimasi parameter GEE menunjukkan kontribusi variabel independen yang digunakan untuk memprediksi nilai variabel dependen volume penjualan, menunjukkan kualitas produk 1-AA $\mathrm{DB}=20 \%$ / high grade 1 berpengaruh terhadap tingkat pembelian produk per konsumen sebesar 24.206 secara signifikan karena nilai sig $0,00<0,05$; Kualitas produk 1 -AA $\mathrm{DB}=60 \%$ / high grade berpengaruh terhadap tingkat pembelian produk per konsumen sebesar 21.633 secara signifik an karena nilai sig $0,00<0,05$; Kualitas produk 1-Sa / local grade 1 berpengaruh terhadap tingkat pembelian produk per konsumen sebesar 5.230 secara signifikan karena nilai sig $0,00<0,05$; Kualitas produk 1-Sc / local grade 2 berpengaruh terhadap tingkat pembelian produk per konsumen sebesar 4.489 secara signifikan karena nilai sig $0,03<0,05$; Kualitas produk $\mathrm{BKH} /$ low grade 1 berpengaruh terhadap tingkat pembelian produk per konsumen sebesar 994 secara tidak signifikan karena nilai sig 0,276 > 0,05; Kualitas produk BP / low grade 2 berpengaruh terhadap tingkat pembelian produk per konsumen sebesar $-88,9$ secara tidak signifikan karena nilai sig 0,956>0,05 dan harga berpengaruh terhadap tingkat pembelian produk per konsumen sebesar $-0,121$ secara signifikan karena nilai sig $0,00<0,05$.

Secara umum, hasilnya menunjukkan bahwa kualitas produk dan harga memiliki pengaruh pada kinerja pemasaran edel cacao PT Perkebunan Nusantara XII yang didekomposisi baik pada volume penjualan dan tingkat pembelian per konsumen namun tidak signifikan pada pertumbuhan jumlah konsumen. Artinya, hasil metode GEE diatas menjelaskan fenomena penurunan penjualan edel cacao yang terjadi selama 2014-2018 relevan dijelaskan akibat adanya penurunan kuantitas pembelian per 
konsumen daripada penurunan jumlah konsumen. Kualitas produk dan fluktuasi harga edel cacao tidak berpengaruh signifikan pada bertambah/berkurangnya jumlah konsumen. Hal itu, dapat dijelaskan melalui representasi permintaan edel cacao PT Perkebunan Nusantara XII beberapa tahun terakhir oleh jumlah konsumen pasar lokal yang terus tumbuh sebesar 76,9\% per tahunnya sementara mengantikan berkurangnya konsumen pasar ekspor sebesar 27,7\% setiap tahunnya (Annual Report PTPN XII, 2010-2018).

Berpalingnya konsumen edel cacao pasar ekspor memberikan kerugian pada perusahaan. Pasar ekspor telah menjadi kontributor utama permintaan kakao jenis edel cacao lebih dari satu dekade. Perusahaan mengalami kesulitan memasarkan edel cacao sejak Uni Eropa memperketat standar kontaminan PAH (Polyclyclic Aromatic Hydrocarbons) yang sebelumnya adalah maksimal sebesar 0,1 ppm (parts per million) menjadi maksimal sebesar 0,1 ppb (parts per billion) pada 2016, permintaan pasar Eropa dan Amerika terhadap edel cacao PT Perkebunan Nusantara XII berkurang sangat signifikan. Pasar Eropa dan Amerika menolak produk kakao PT Perkebunan Nusantara XII yang diproses dengan menggunakan teknik pengasapan, hal tersebut dianggap tidak ramah lingkungan dan tidak memenuhi standar PAH terbaru. Salah satu dampak dari berlakunya kebijakan ini adalah penjualan edel cacao PT Perkebunan Nusantara XII di tahun 2017 mengalami underdelivered terendah sejak mulai di perdagangkan di bursa komoditas, ditengah-tengah permintaan kakao yang terus meningkat di seluruh dunia.

Secara spesifik, diantara variabel yang diukur, menunjukkan bahwa baik pada volume penjualan dan tingkat pembelian per konsumen, kualitas produk adalah faktor utama (partial eta squared sebesar 22,9\% sementara harga sebesar 3\%). Model estimasi parameter GEE memberikan informasi bahwa kualitas produk $1,2,3$, dan 4 (1-AA $\mathrm{DB}=20 \%, 1-\mathrm{AA} \mathrm{DB}=60 \%, 1-\mathrm{Sa}$ dan 1 -Sc) memiliki pengaruh signifikan pada volume penjualan dan tingkat pembelian per konsumen sementara tiga kualitas lainnya tidak memiliki pengaruh signifikan pada variabel dependen. Artinya, meningkat/menurunnya variabel dependen yaitu volume penjualan dan tingkat pembelian per konsumen didorong oleh penawaran kualitas produk 1 (1-AA DB=20\%), 2 (1-AA DB=60\%), 3 (1-Sa) dan 4 (1-Sc). Lebih lanjut, variabel harga pada ketiga model parameter estimasi GEE menunjukkan hubungan negatif. Artinya, konsumen mungkin cenderung menaruh minat pada pembelian edel cacao high quality dan bersedia membayar untuk harga yang tinggi, namun kenaikan harga produk akan cenderung mengakibatkan penurunan tingkat pembelian per konsumen dan penurunan volume penjualan, sebaliknya penurunan harga produk cenderung mengakibatkan kenaikan tingkat pembelian per konsumen dan kenaikan volume penjualan.

\section{KESIMPULAN}

Pada penelitian ini kinerja pemasaran diukur melalui volume penjualan, pertumbuhan jumlah konsumen dan tingkat pembelian produk per konsumen. Melalui GEE diperoleh bahwa kualitas produk dan harga secara simultan berpengaruh signifikan terhadap volume penjualan edel cacao periode 2014-2018, kemudian kualitas produk dan harga secara simultan berpengaruh terhadap tingkat pembelian produk per konsumen periode 2014-2018, dan kualitas produk dan harga secara simultan tidak berpengaruh signifikan terhadap pertumbuhan jumlah konsumen edel cacao periode 2014-2018. Penurunan kinerja pemasaran edel cacao dijelaskan melalui penurunan tingkat pembelian produk oleh setiap konsumen. Konsumen pasar domestik terus mengalami pertumbuhan sementara konsumen pasar ekspor berkurang. Sejak diberlakukannya kebijakan baru perihal pengelolaan kakao dan standar PAH oleh Uni Eropa, permintaan edel cacao PT Perkebunan Nusantara XII di pasar internasional menurun drastis. Pada banyak penelitian, pertumbuhan jumlah konsumen dapat diidentifikasi sebagai ukuran dari perluasan pangsa pasar atau juga ekspansi, sementara tingkat pembelian produk per konsumen dapat diidentifikasi lebih pada ukuran loyalitas konsumen. Maka pada penelitian ini mengidentifikasi bahwa loyalitas konsumen edel cacao PT Perkebunan Nusantara XII cenderung rendah. 
Retno Cahyaningtyas Puji Lestari. Studi Kinerja Pemasaran Edel Cacao: Peran Kualitas Produk dan Harga

Profesional pemasaran PT Perkebunan Nusantara XII (Persero) Surabaya disarankan untuk merangsang peningkatan jumlah konsumen dan/ atau tingkat pembelian per konsumen untuk meningkatkan volume penjualan edel cacao. Meskipun melalui hasil GEE di atas menunjukkan adanya pola pengaruh terhadap kinerja pemasaran secara menyeluruh, namun kualitas produk dan harga tidak memiliki pengaruh signifikan terhadap pertumbuhan jumlah konsumen. Beberapa penelitian, mengidentifikasi tingkat pembelian per konsumen lebih pada ukuran loyalitas konsumen. Jika perusahaan memutuskan untuk merangsang peningkatan penjualan melalui tingkat pembelian per konsumen maka perusahaan perlu menargetkan kegiatan-kegiatan pemasaran yang berkaitan dengan upaya menjaga loyalitas konsumen, dapat berupa menjaga kualitas produk, emotional bonding, kepuasan konsumen, kepercayaan, dan lain-lain. Pertumbuhan jumlah konsumen dapat mengidentifikasi ukuran dari pertumbuhan pangsa pasar atau ekspansi. Dalam upaya meningkatkan jumlah konsumen, pada beberapa penelitian lainnya mengungkapkan strategi penetrasi pasar adalah yang paling tepat. Penetrasi pasar dapat dilakukan dengan cara penetapan harga yang lebih rendah, inovasi produk baru, promosi secara luas dan lain-lain. Regulasi keamanan dan kesehatan pangan, kelompok referensi, promosi, inovasi produk, Corporate Social Responsibility (CSR), 6) Customer Relationship Management (CRM) dapat diagendakan untuk dilibatkan dalam penelitian selanjutnya.

\section{DAFTAR PUSTAKA}

Adewale, G. (2013). Impact of Marketing Strategy on Business Performance A Study of Selected Small and Medium Enterprises (Smes) In Oluyole Local Government, Ibadan, Nigeria. IOSR Journal of Business and Management, 11(4), 59-66.

Allaoui mohammed elhassen, Tidjani chemseddine, O. B. (n.d.). "The Importance of Training Programs in the Improvement of the Performance of Employees In The Petroleum Companies"- Case of Sonatrach Company - The Regional Directorate of BERKAOUI (Ouargla- Algeria) . Saudi Journal of Business and Management Studies, 433-445.

Asean Today Team, 2019. Produsen Utama Kakao ASEAN sedang Berjuang untuk Mengatasi Meningkatnya Permintaan untuk Coklat. (https://www.aseantoday.com/2019/06/aseans-topcocoa-bean-producers-are-struggling-to-cope-with-increasing-demand-for-chocolate/?lang=id, diakses pada 28 Januari 2020)

Basu, Swastha dan Hani Handoko. (2012). Manajemen Pemasaran-Analisis Perilaku Konsumen. Yogyakarta: BPFE

Basu, Swastha dan Irawan. (2008). Manajemen Pemasaran Modern. Yogyakarta: Liberty

Budidharmo, Susanto. (2000). Dasar-Dasar Manajemen Pemasaran. Yogyakarta: CAPS

Dwijayani, H. (2013). Analysis of Effect of Price, Location And Services to Increase Sales Volume. Improving the Quality of Education to Face the Impact of Technology, 1(December), 586-588.

Elise Dwi Ratnasari \& bel, CNN Indonesia. 2018. Cerita 'Pahit' di Balik Manisnya Cokelat. (https://www.cnnindonesia.com/gaya-hidup/20180706184749-267-312123/cerita-pahit-dibalik-manisnya-cokelat, diakses 6 Desember 2019)

FAO. 2019. Food and Agriculture Organization of The United Nations. (http://www.fao.org/faostat/en/\#data/QC/visualize, diakses pada 2 Februari 2020)

Farris, P. W., Bendle, N. T., Pfeifer, P. E., \& Reibstein, D. J. (2010). Marketing Metrics, Second Edition The Definitive Guide to Measuring Marketing Performance.

Foxall, G. R. (2009). Consumer behavior analysis. The SAGE Handbook of Marketing Theory, 299315. 
Froehle, C. M., Roth, A. V., Chase, R. B., \& Voss, C. A. (2000). Antecedents of new service development effectiveness: An exploratory examination of strategic operations choices. Journal of Service Research, 3(1), 3-17.

Harlan, Johan. (2018). Analisis Data Longitudinal. Depok: Gunadarma

Karam, A. A., Hamo, R. H., Rashid, H. M., Jarjes, D. A., Mohammed, C. S., \& Obaid, S. H. (2018). The Effect of Marketing Strategy Implementation on Organization Performance as a Private Business: Case of Cihan University Duhok Camps KRG-Iraq. International Journal of Business Management and Economic Research(IJBMER), 9(3), 1281-1295.

Kotler, Philip dan Kevin Lane Keller. (2009). Manajemen Pemasaran Edisi 13. Terjemahan Bob Sabran. Jakarta : Erlangga

Kotler, Philip dan Gary Amstrong. (2012). Prinsip-Prinsip Pemasaran Edisi 13 Jilid I. Jakarta: Erlangga

Moekijat. (2000). Kamus Manajemen. Bandung: Mandar Maju

Olasunkanmi, S. (2013). I j c r b. 485-496.

Oliveira-castro, J. M., James, V. K., \& Foxall, G. R. (2007). COMPARING INTERPURCHASE TIMES ACROSS PRODUCTS AND CONSUMERS. 483-500.

Pelham, A. M., \& Wilson, D. T. (1996). A longitudinal study of the impact of market structure, firm structure, strategy, and market orientation culture on dimensions of small-firm performance. Journal of the Academy of Marketing Science, 24(1), 27-43.

Portal Publik PTPN XII. (2011). PTPN XII, Ekspansi dengan Penuh Inovasi. (http://www.bumn.go.id/ptpn12/berita/1583, diakses 2 Januari 2020)

Porto, R. B., de Oliveira-Castro, J. M., \& Seco-Ferreira, D. C. (2011). What consumers say and do: Planned and actual amounts bought in relation to brand benefits. Service Industries Journal, 31(15), 2559-2570.

Porto, R., \& Lima, N. (2015). Nonlinear Impact of the Marketing Mix on Brand Sales Performance. Brazilian Business Review, 12(5), 57-77.

PT Perkebunan Nusantara XII. (2019). Edel cacao, Finest Cocoa Variety. (https://ptpn12.com/2019/07/09/kakao-edel-finest-cocoa-variety/, diakses 3 Desember 2020)

PT Perkebunan Nusantara XII (Persero). (2015). Annual Report 2015. Surabaya: PT Perkebunan Nusantara XII (Persero)

PT Perkebunan Nusantara XII (Persero). (2016). Annual Report 2016. Surabaya: PT Perkebunan Nusantara XII (Persero)

PT Perkebunan Nusantara XII (Persero). (2017). Annual Report 2017. Surabaya: PT Perkebunan Nusantara XII (Persero)

PT Perkebunan Nusantara XII (Persero). (2018). Annual Report 2018. Surabaya: PT Perkebunan Nusantara XII (Persero)

Report, G. M. (2010). Global Market Report. Exchange Organizational Behavior Teaching Journal, 62. 
Retno Cahyaningtyas Puji Lestari. Studi Kinerja Pemasaran Edel Cacao: Peran Kualitas Produk dan Harga

Saragih, H. (2017). Analisis Faktor Pendorong Pemasaran Ekspor Dan Pengaruhnya Terhadap Peningkatan Volume Penjualan Pada Pt. Perkebunan Nusantara Ii (Persero) Medan. Jurnal Ilmiah Methonomi, 3(2), 149-163.

Sarwono, Jonathan, 2014. Riset Skripsi dan Tesis dengan SPSS 22. Jakarta : PT Elex Media Komputindo

Schroth, G., Läderach, P., Martinez-Valle, A. I., Bunn, C., \& Jassogne, L. (2016). Vulnerability to climate change of cocoa in West Africa: Patterns, opportunities and limits to adaptation. Science of the Total Environment, 556, 231-241.

Tjiptono, Fandy. (2008). Strategi Pemasaran, Edisi Ketiga. Yogyakarta: Andi Offset

Tjiptono, Fandy dan Gregorius Chandra. (2011). Service, Quality \& Satisfaction. Yogyakarta : Andi Offset.

The International Institute for Sustainable Development. (2019). Global Market Report: Cocoa. (https://www.iisd.org/sites/default/files/publications/ssi-global-market-report-cocoa.pdf, diakses pada 13 Januari 2020)

William, J. Stanton. 2006. Dasar-dasar Manajemen. Jakarta: Mandar Maju

Winardi. (2001). Kepemimpinan dalam Manajemen. Jakarta: Raja Grafindo Persada 